\title{
PROPOSTA E ANÁLISE DE UMA SEQUÊNCIA DIDÁTICA PARA ABORDAR UMA EDUCAÇÃO AMBIENTAL SOB ENFOQUE CTS
}

\section{PROPOSAL AND ANALYSIS OF A DIDACTIC SEQUENCE TO APPROACH AN ENVIRONMENTAL EDUCATION UNDER THE CTS APPROACH}

\author{
Mylena Guedes Passeri ${ }^{1}$, Marcelo Borges Rocha ${ }^{2}$ \\ ${ }^{1}$ Centro Federal de Educação Tecnológica Celso Suckow da Fonseca, mylena.passeri@gmail.com \\ ${ }^{2}$ Centro Federal de Educação Tecnológica Celso Suckow da Fonseca, rochamarcelo36@yahoo.com.br
}

\begin{abstract}
RESUMO
Uma alfabetização científico-tecnológica ampliada inclui o entendimento das relações entre ciência, tecnologia e sociedade (CTS) e estimula um posicionamento mais informado frente aos problemas socioambientais. Neste trabalho, analisamos uma sequência didática aplicada a 30 alunos do Ensino Médio para abordar questões socioambientais com viés CTS. Percebe-se que a maioria dos estudantes declara ter interesse sobre questões ambientais e utilizam de meios digitais como fonte de informações. Além disso, a maior parte dos alunos admite que os atuais níveis de consumo não são sustentáveis. Porém, grande parte dessas respostas não apresenta argumentos ou estes não são bem desenvolvidos. Através de um levantamento das expectativas e atitudes ambientais dos estudantes, concluiu-se que o lixo foi o assunto mais mencionado. Por isso, temas vinculados a cadeia de extração, produção, consumo e descarte de bens foram planejados para serem mais aprofundados nos encontros posteriores.
\end{abstract}

Palavras-chave: temas socioambientais, educação ambiental, CTS, sequência didática.

\begin{abstract}
A broader scientific-technological literacy includes understanding the relationships between science, technology and society (STS) and stimulates a more informed positioning regarding socio-environmental problems. In this work, we analyzed a didactic sequence applied to 30 high school students to address social and environmental issues with STS bias. It is noticed that the majority of the students declares to have interest on environmental questions and use of digital means like source of information. In addition, most students admit that current levels of consumption are not sustainable. However, most of these answers do not present arguments or are not well developed. Through a survey of students environmental expectations and attitudes, it was concluded that garbage was the most mentioned subject. Therefore, issues related to the chain of extraction, production, consumption and disposal of goods were planned to be further elaborated in the later meetings.
\end{abstract}

Key words: socioenvironmental themes, environmental education, STS, didactic sequence.

\section{INTRODUÇÃO}

Biologia, Química e Física são componentes curriculares que integram o estudo das Ciências da Natureza no Ensino Médio (EM). O Ensino de Ciências aborda 


\title{
Ensino, Saúde e Ambiente - V10 (2), pp. 1-15, Ago. 2017
}

variados temas relacionados a situações cotidianas que não podem ser ignoradas, como "o avanço do uso da energia nuclear; da nanotecnologia; a conquista da produção de alimentos geneticamente modificados; a clonagem biológica" (BRASIL, 2013, p. 26).

Nesse contexto, Krasilchik (2000, p. 89) defende que a "admissão das conexões entre a ciência e a sociedade implica que o ensino não se limite aos aspectos internos à investigação científica, mas à correlação destes com aspectos políticos, econômicos e culturais". Concordando com essa proposição, Auler e Delizoicov (2001) complementam que tal entendimento faz parte de uma alfabetização científicotecnológica (ACT) ampliada e mais qualificada, que inclui o entendimento das múltiplas relações entre ciência, tecnologia e sociedade (CTS) (PRAIA; GIL-PÉREZ; VILCHES, 2007; VILAS BOAS et al., 2013).

As Diretrizes Curriculares Nacionais Gerais da Educação Básica (DCNGEB) evidenciam a importância do tratamento dessas questões na Educação Básica ao destacarem que "o conhecimento científico e as novas tecnologias constituem-se, cada vez mais, condição para que a pessoa saiba se posicionar frente a processos e inovações que a afetam" (BRASIL, 2013, p. 26) e que:

\begin{abstract}
Uma formação integral [...] promove a reflexão crítica sobre os padrões culturais que se constituem normas de conduta de um grupo social, assim como a apropriação de referências e tendências que se manifestam em tempos e espaços históricos, os quais expressam concepções, problemas, crises e potenciais de uma sociedade, que se vê traduzida e/ou questionada nas suas manifestações. Assim, evidencia-se a unicidade entre as dimensões científico-tecnológico-cultural, a partir da compreensão do trabalho em seu sentido ontológico. (BRASIL, 2013, p. 162).
\end{abstract}

Krasilchik (2000, p. 85) aponta que "na medida em que a Ciência e a Tecnologia foram reconhecidas como essenciais no desenvolvimento econômico, cultural e social, o ensino das Ciências em todos os níveis foi também crescendo de importância".

Dentro do contexto científico e tecnológico, em especial, na área biológica, as questões ambientais ganham destaque devido aos problemas socioambientais observados, como as "mudanças climáticas, a degradação da natureza, a redução da biodiversidade, os riscos socioambientais locais e globais, as necessidades planetárias" (BRASIL, 2013, p. 542). Entende-se a prática de uma Educação Ambiental (EA) como estratégia importante para mitigar tais problemas. De acordo com Jacobi (2003) e Quintas (2004), a EA se caracteriza como uma área complexa que integra e relaciona aspectos sociais, ecológicos, políticos, culturais, econômicos, científicos, tecnológicos, entre outros. 
Apesar da importância do tratamento de tais temas, o ensino de forma geral pode se mostrar monótono ou cansativo ao longo do ano letivo, por isso, é importante o desenvolvimento de metodologias diferenciadas da rotina semanal de sala de aula para que alunos e professores se sintam mais atraídos e estimulados.

Um dos desafios relatados por professores é a "dificuldade de fazer com que os alunos se interessem pelos estudos e prestem atenção" (NOVA ESCOLA, 2014, p. 24). Nesse contexto, o papel do professor no planejamento, nas reflexões sobre a didática e sua atualização se evidencia para que haja uma boa gestão de sala de aula (NOVA ESCOLA, 2014).

Diante deste cenário, neste trabalho busca-se defender a importância do tratamento de temas sociocientíficos no EM a partir de estratégias didáticas variadas, com foco em uma sequência didática (SD). Apresenta-se o planejamento, a aplicação e a análise dos frutos de uma SD que buscou a promoção de uma ACT qualificada, com foco em questões ambientais a partir de um contexto CTS, com estudantes do EM.

\section{ALFABETIZAÇÃO CIENTÍFICO-TECNOLÓGICA E SEQUÊNCIA DIDÁTICA}

Dentre as finalidades do EM, de acordo com a LDB, temos a formação ética do indivíduo, o desenvolvimento da autonomia intelectual, do pensamento crítico e o domínio dos conhecimentos científico-tecnológicos, relacionando-os ao modelo de produção de bens (BRASIL, 1996, art. 35, incisos II, III e IV).

De forma correlata, Zabala e Arnau (2007) defendem que os problemas da realidade são únicos e complexos e para que os indivíduos possam enfrentá-los e atuar de forma eficaz precisam ter competências desenvolvidas a partir de componentes atitudinais, procedimentais e conceituais. Nesse contexto, o ensino escolar pode oferecer situações variadas de estudo e propiciar o desenvolvimento de tais competências.

Estando presente de forma marcante no cotidiano da população, em especial pelos progressos da internet, os avanços científico-tecnológicos se destacam - como as terapias gênicas, manipulações genéticas e as relações entre o desenvolvimento da ciência e da tecnologia com as questões socioambientais. Auler (2003, p. 69) enfatiza que a ACT tem sido um tema cada vez mais recorrente no ensino e aprendizagem devido a atual "dinâmica social crescentemente relacionada ao desenvolvimento científico-tecnológico".

Auler e Delizoicov (2001) e Reis e Galvão (2004) defendem ainda uma ACT 


\section{Ensino, Saúde e Ambiente - V10 (2), pp. 1-15, Ago. 2017}

numa visão ampliada, na qual se estimula discussões críticas e contextualizadas, possibilitando a superação de alguns mitos científicos comumente observados na população, como: a visão dominante de decisões tecnocráticas, a visão salvacionista da CT e o determinismo tecnológico. Auler e Delizoicov (2001, p. 6) sugerem que nessa abordagem mais complexa, "os conteúdos são considerados como meios para a compreensão de temas socialmente relevantes" e as relações CTS são tratadas de maneira problematizada e contextualizada.

Acevedo-Díaz, Manassero-Mas e Vázquez-Alonso (2002, p. 24, tradução livre) concordam com tais colocações, enfatizando que a mesma "promove a possibilidade de uma participação responsável, bem informada e com fundamentos, dos cidadãos nas políticas científicas e tecnológicas para um desenvolvimento mais justo e sustentável".

No que tange a situação ambiental, a Constituição Federal (BRASIL, 1988) defende a sadia qualidade de vida da população. No entanto, a degradação ambiental e as desigualdades sociais estão provocando uma crise moderna que vem sendo denominada de crise socioambiental que exige estratégias urgentes para sua superação (JACOBI, 2003; QUINTAS, 2004).

A partir do entendimento das complexas imbricações sociais, políticas, econômicas, morais, ambientais entre outras que estão inseridas na atividade científicotecnológica, os estudantes estariam mais aptos a conhecer de forma mais completa as causas, o funcionamento e as consequências do desenvolvimento CT e, assim, opinar e decidir de forma mais democrática sobre temas e problemas sociais, científicos e tecnológicos presentes em sua realidade.

Nesse sentido, o tratamento de uma EA, sob enfoque CTS, se mostra interessante para um aprendizado integral e contextualizado, condizente com uma ACT ampliada, preparando o indivíduo para ser um ator social participativo e crítico frente aos problemas e conflitos socioambientais (AULER; DELIZOICOV, 2001; JACOBI, 2003; QUINTAS, 2004).

No contexto escolar, o papel do professor é fundamental, já que atua diretamente no planejamento e realização de atividades desenvolvidas, muitas vezes atuando como intermediário entre os conteúdos escolares e o aprendizado dos alunos (NOVA ESCOLA, 2014). As Orientações Curriculares para o Ensino Médio indicam ainda que os docentes devem estar preparados para apresentar os conteúdos "de maneira a possibilitar que o aluno associe a realidade do desenvolvimento científico atual com os conceitos básicos do pensamento biológico" (BRASIL, 2006, p. 15), apoiando a ideia 
de uma ACT com enfoque CTS.

No entanto, Krasilchik (2000, p. 88) aponta que faltam "discussões que permitam ao próprio docente nas atuais condições de trabalho criar um clima de liberdade intelectual, que não limite a sua atividade a exposições, leitura ou cópia de textos". Portanto, mudanças são necessárias para vencer os desafios impostos, como a reorganização curricular, a revisão da formação inicial e continuada dos professores e a obtenção de financiamento e subsídios para infraestrutura e realização das atividades de forma eficiente (NOVA ESCOLA, 2014).

Considerando ainda as individualidades dos estudantes, destaca-se a importância e o papel das diversificadas estratégias didáticas. Assim, a superação de um ensino meramente expositivo, focado na transmissão de informações organizadas pelo professor para um ensino contextualizado, questionador e diversificado colabora para a interpretação e a leitura do mundo atual que deve ser desenvolvida pelos diferentes estudantes (ZABALA; ARNAU, 2007).

Para tanto, novas metodologias precisam ser pensadas e analisadas quanto à sua efetividade em atrair o interesse dos jovens e auxiliar no processo de ensino e aprendizagem. Diante disso, destaca-se a importância de trabalhos investigativos com proposições práticas e embasamentos teóricos para a atuação de professores na escola.

Nesse contexto, as SDs se apresentam como ferramentas interessantes, pois

[...] apresentam uma grande variedade de atividades que devem ser selecionadas, adaptadas e transformadas em função das necessidades dos alunos, dos momentos escolhidos para o trabalho, da história didática do grupo e da complementaridade em relação a outras situações de aprendizagens [...], propostas fora do contexto das seqüências [sic] didáticas (DOLZ; NOVERRAZ; SCHNEUWLY, 2004, p.110).

De acordo com Zabala (1998, p.18), uma sequência didática pode ser definida como "um conjunto de atividades ordenadas, estruturadas e articuladas para a realização de certos objetivos educacionais, que têm um princípio e um fim conhecidos tanto pelos professores como pelos alunos". Para o delineamento da SD, utilizou-se o modelo básico evidenciado Dolz, Noverraz e Schneuwly (2004, p. 97) (figura 1). Nesta pesquisa, chamaremos os "módulos" de "encontros".

Figura 1: Esquema geral de uma SD.

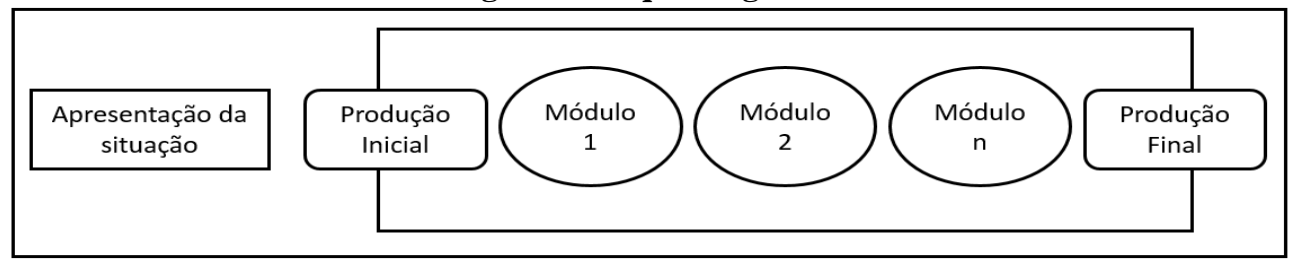

Fonte: Baseado em Dolz, Noverraz e Schneuwly (2004, p. 97). 


\section{Ensino, Saúde e Ambiente - V10 (2), pp. 1-15, Ago. 2017}

Dolz, Noverraz e Schneuwly (2004) informam que a apresentação inicial da situação é um momento importante de reconhecimento das partes envolvidas na SD, tanto em relação aos atores, aos conteúdos que serão trabalhados, aos objetivos e às atividades que deverão ser cumpridas. Considerando a fase de produção inicial como um meio de diagnosticar as dificuldades, interesses e potencialidades dos alunos, partese para o planejamento dos módulos, que devem oferecer subsídios para a superação dos entraves observados.

O uso de módulos de aprendizagem é um princípio geral quando se fala em SD e estes devem ser organizados de acordo com uma sequência lógica e complementar de objetivos e atividades, de forma que uma sirva de base para outra. Esta estratégia "se inscreve numa perspectiva construtivista, interacionista e social que supõe a realização de atividades intencionais, estruturadas e intensivas que devem adaptar-se às necessidades particulares dos diferentes grupos de aprendizes" (DOLZ; NOVERRAZ; SCHNEUWLY, 2004, p. 110).

Na última etapa, a produção final, os estudantes têm a oportunidade de mostrar o que foi aprendido, o que pode ser analisado a partir de mudanças observadas em relação ao início da $\mathrm{SD}$, considerando os conceitos, conhecimentos, vocabulário usado, participação e interesse manifestados.

Nesse contexto, ressalta-se que o uso de diferentes percursos metodológicos é fundamental para alcançar as potencialidades de um grupo heterogêneo, como o que se costuma observar em uma turma de estudantes.

\section{METODOLOGIA}

Baseando-se nos pressupostos de Gil (2010, p.1), esta investigação caracterizase como uma pesquisa-ação, já que inclui estratégias participativas e propõe intervenções, no formato de uma SD, a partir de dados coletados no próprio grupo ao longo do estudo.

A partir do entendimento da importância da promoção de uma EA num contexto CTS para a alfabetização científica e tecnológica dos estudantes e das diferentes estratégias didáticas que podem ser utilizadas para potencializar o ensinoaprendizagem, buscou-se investigar sobre o planejamento de uma sequência didática para a discussão de questões ambientais no EM, esperando identificar ao longo das atividades, interesses e limitações dos estudantes sobre o assunto.

Buscou-se, então, fazer um levantamento dos temas socioambientais mais 


\section{Ensino, Saúde e Ambiente - V10 (2), pp. 1-15, Ago. 2017}

mencionados pelos estudantes a partir de seus conhecimentos prévios, identificar expectativas do grupo de estudantes em relação as questões socioambientais e planejar de que forma os temas socioambientais relatados pelos estudantes podem ser trabalhados em uma SD.

Foram selecionadas todas as turmas do EM de um colégio particular localizado no município de Belford Roxo, Baixada Fluminense, região metropolitana do Rio de Janeiro. A escola foi escolhida pela disponibilidade da professora titular em oferecer suas turmas para o desenvolvimento da pesquisa. O segmento do EM foi elegido devido às estratégias metodológicas pensadas para a SD ser voltadas para este público, que permite maior aprofundamento e complexidade nas discussões. Durante a aplicação da sequência didática, a pesquisadora assumiu a regência do grupo de estudantes. Assim, todo o desenvolvimento da SD foi realizado pela pesquisadora. No total, trinta alunos participaram do estudo.

A coleta de dados foi realizada ao longo do processo através de registros escritos no formato de diário de bordo, atividades escritas discursivas e questionários. Neste trabalho, são apresentadas as análises a partir do questionário inicial e da lista de hábitos e atitudes preenchidos pelos estudantes. O diário de bordo auxiliou no processo de interpretação e análise das respostas dos estudantes.

De acordo com Gil (2010, p. 154), a análise e interpretação de dados de uma pesquisa-ação podem considerar etapas clássicas de análise: “categorização, codificação, tabulação, análise estatística e generalização", ou ainda privilegiar "a discussão em torno dos dados obtidos, de onde decorre a interpretação de seus resultados". Os dados dos questionários e da lista de hábitos e atitudes serão analisados de forma qualitativa a partir dos referenciais da análise de conteúdo categorial (AC). Bardin (1979, p. 115) esclarece que a abordagem qualitativa "corresponde a um procedimento mais intuitivo, (...) mais maleável e mais adaptável, a índices não previstos, ou a evolução das hipóteses".

A AC tem como etapas fundamentais: categorização, descrição e interpretação dos dados. A organização da análise seguiu as etapas orientadas por Bardin (1979) de pré-análise, exploração do material e, por fim, o tratamento, as inferências e a interpretação dos dados.

$\mathrm{Na}$ pré-análise foi esquematizada a organização geral dos resultados e do trabalho. A leitura flutuante do material permitiu o aparecimento de ideias para a análise. Nesta fase, as categorias começaram a ser refletidas e algumas foram sendo 


\section{Ensino, Saúde e Ambiente - V10 (2), pp. 1-15, Ago. 2017}

anotadas para posterior utilização.

Na fase de exploração do material, ocorreu a codificação do material visando facilitar a organização da análise e impedir o reconhecimento dos alunos. Utilizaram-se códigos alfanuméricos compostos pela letra "A" seguida de um número para se referir aos estudantes. Dessa forma, os números são exclusivos e identificam alunos diferentes.

Ao longo da análise, a presença de palavras e temas semelhantes nos diferentes textos foram os indicadores usados para estabelecer agrupamentos, como orienta Bardin (1979). A partir da análise dos dados, foram elaborados quadros e sistematizações. Além disso, reflexões iniciais foram sendo registradas para posterior análise e discussão com os demais dados.

\section{RESULTADOS E DISCUSSÃO}

Ao elaborar a SD, optamos por seguir como princípios norteadores: priorizar os temas mais relevantes para o contexto social dos estudantes e para o interesse demonstrado pelos alunos ao preencherem as atividades do questionário inicial e a atividade escrita de lista de hábitos e atitudes; explorar a interdisciplinaridade dos assuntos; contextualizar as situações problemas para que possam estimular mais a curiosidade e o interesse dos estudantes; oferecer informações baseadas em estudos e/ou legislações vigentes para ampliar a gama e o tipo de fonte de conhecimentos desses alunos; estimular as discussões baseadas em argumentos, o respeito por opiniões divergentes, a participação ativa, a curiosidade e a mudança de valores e atitudes individuais e coletivas. Destacamos que estes aspectos axiológicos não são foco de análise neste trabalho.

Tais princípios auxiliam a alcançar os objetivos propostos, trabalhando de forma a minimizar problemas trazidos pelos próprios alunos (através das atividades iniciais) ao longo da SD trabalhada.

A partir de pesquisa bibliográfica, delineou-se uma SD inicial. Foram realizados três encontros, com duração de duas horas, em horário de contra turno, no período da tarde. Foram utilizados recursos como datashow, caixa de som, vídeos, imagens, quadro branco, canetas, papeis, entre outros. O software Microsoft Office PowerPoint ${ }^{\circledR} 2013$ foi utilizado para construção de apresentações textuais e imagéticas que orientaram as discussões e os temas trabalhados ao longo de cada encontro.

A abordagem usada ao longo da SD priorizou o uso de questionamentos, oferecendo subsídios e oportunidades para manifestação dos alunos, e o estímulo ao 
debate de ideias baseado em argumentações informadas. As conceituações e posicionamentos abordados foram pautados em bibliografia da área e em legislações e políticas. Isto favorece a ampliação das fontes de consulta dos estudantes e a própria interpretação da linguagem mais erudita e técnica presente nas leis e políticas.

Na tabela 1 são apresentados os assuntos tratados, assim como os recursos utilizados em cada encontro.

Tabela 1: Sistematização dos conteúdos abordados e recursos utilizados em cada encontro da SD.

\begin{tabular}{|c|l|l|}
\hline Encontro & Conteúdos/Assuntos abordados & Recursos utilizados \\
\hline $\mathbf{1}$ & $\begin{array}{l}\text { Meio ambiente/ambiente, recursos naturais e } \\
\text { impacto ambiental. }\end{array}$ & $\begin{array}{l}\text { Datashow, caixa de som, questionário } \\
\text { inicial e outras atividades escritas. }\end{array}$ \\
\hline $\mathbf{2}$ & $\begin{array}{l}\text { Conceituação, eventos e histórico da EA, } \\
\text { sustentabilidade, crise socioambiental, recursos } \\
\text { naturais, sua exploração e impactos. }\end{array}$ & $\begin{array}{l}\text { Datashow, caixa de som, vídeos: } \\
\text { discursos de Severn Cullis-Suzuki - } \\
\text { Rio-92 e Rio+20, "História das } \\
\text { Coisas" e Animação "Homem". }\end{array}$ \\
\hline 3 & $\begin{array}{l}\text { Cadeia de produção de bens e ciclo de vida dos } \\
\text { produtos, consumo e hiperconsumo, destinação } \\
\text { de resíduos sólidos, biomas (em especial, Mata } \\
\text { Atlântica), Unidades de Conservação, poder de } \\
\text { escolha, alternativas minimizadoras dos danos } \\
\text { ambientais, cidadania. }\end{array}$ & $\begin{array}{l}\text { Datashow, caixa de som, } \\
\text { das Flores" e produção final. }\end{array}$ \\
\hline
\end{tabular}

Fonte: Autoria própria.

O Questionário inicial abaixo (figura 2) foi aplicado no encontro 1 da SD.

Figura 2: Questionário inicial aplicado aos alunos no encontro 1 da SD.

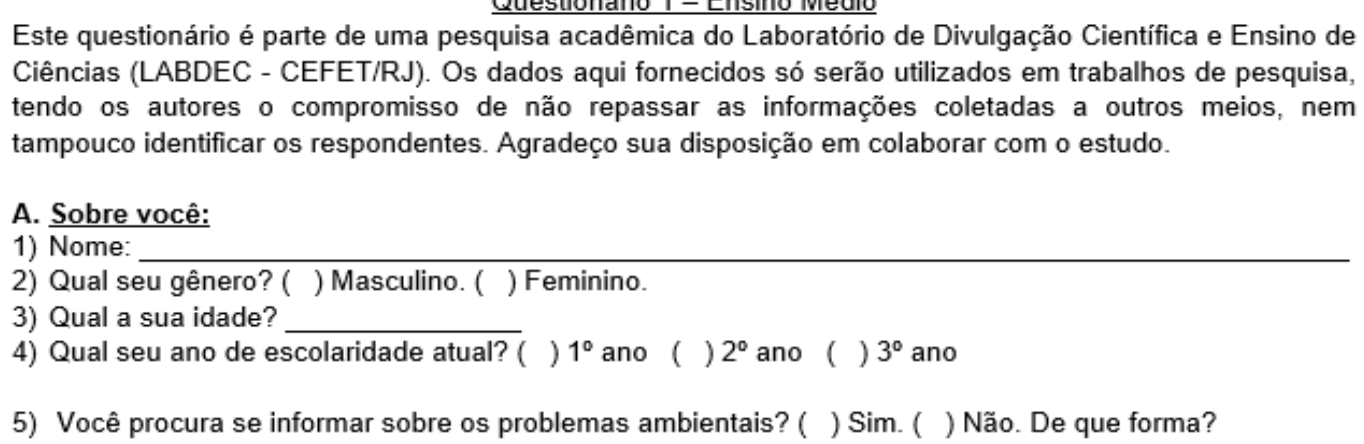

6) Com os atuais níveis de consumo de materiais e produtos observados na sociedade você acha que o planeta tem condições de se sustentar? ( ) Sim. ( ) Não. Explique:

7) Escreva algumas dúvidas que você gostaria de esclarecer sobre os temas a seguir: questões ambientais, Unidades de Conservação, biomas, recursos naturais e consumo. 
O objetivo desta atividade era reconhecer o perfil da turma, que não é o foco desta análise, para facilitar o contato em posteriores encontros. Além disso, também foram solicitadas respostas associadas ao interesse e a opinião dos estudantes sobre as questões ambientais. Cada questão foi analisada de forma separada e é apresentada a seguir.

O intuito da questão 5: "Você procura se informar sobre os problemas ambientais? ( ) Sim. （ ） Não. De que forma?" era perceber o interesse dos jovens por informações sobre os problemas ambientais e fazer uma percepção rápida dos meios que estes utilizam como fontes.

A categorização foi feita agrupando as respostas em Sim ou Não. Sobre as fontes de consulta apontadas, foram feitos subagrupamentos de acordo com o tipo de meio de comunicação, assim, foram criadas duas subcategorias para a categoria "Sim". Esses dados estão apresentados na tabela 2.

Tabela 2: Categorias, subcategorias e comentários/exemplos da questão 5.

\begin{tabular}{|c|c|c|}
\hline $\begin{array}{l}\text { Categorias da } \\
\text { questão } 5 \text { - } \\
\text { quant. de resp. }\end{array}$ & $\begin{array}{l}\text { Subcategorias - quant. } \\
\text { de resp. }\end{array}$ & Comentários/Exemplos \\
\hline Não - 10 & Sem subcategorias & $\begin{array}{l}\text { Na resposta transcrita a seguir, apesar de assumir não } \\
\text { procurar saber sobre os problemas ambientais, o } \\
\text { estudante manifesta interesse pelo assunto: "Isso } \\
\text { interessa, mais não sou de me informar sobre" (A17) }\end{array}$ \\
\hline \multirow[t]{2}{*}{ Sim - 16} & $\begin{array}{l}\text { Meios impressos } \\
\text { (jornais e revistas) - } 8\end{array}$ & \multirow{2}{*}{$\begin{array}{l}\text { O avanço das comunicações por meio das redes de } \\
\text { internet e a facilidade de acesso a computadores, } \\
\text { celulares e equipamentos semelhantes com acesso à } \\
\text { internet podem ser fatores que estejam estimulando a } \\
\text { busca de informações mais intensa através desses meios. }\end{array}$} \\
\hline & $\begin{array}{l}\text { Meios digitais } \\
\text { (internet, redes sociais, } \\
\text { televisã o e vídeos) - } 19\end{array}$ & \\
\hline
\end{tabular}

Fonte: Autoria própria.

Percebe-se que a maioria dos estudantes afirma buscar informações sobre os problemas ambientais, o que pode estar relacionado a um possível interesse dos mesmos sobre essas questões.

A questão 6 "Com os atuais níveis de consumo de materiais e produtos observados na sociedade você acha que o planeta tem condições de se sustentar? ( ) Sim. ( ) Não. Explique.” foi elaborada para perceber a argumentação das respostas que os estudantes apresentariam.

As respostas com mais argumentos desenvolvidos foram consideradas mais complexas ou melhores informadas. Ao analisar os dados referentes a essa questão, foram criadas três categorias: Sim, Não sei e Não, que estão apresentadas na tabela 3. 


\section{Ensino, Saúde e Ambiente - V10 (2), pp. 1-15, Ago. 2017}

Tabela 3: Categorias, subcategorias e comentários/exemplos da questão 6.

\begin{tabular}{|c|c|c|}
\hline $\begin{array}{l}\text { Categorias da } \\
\text { questão } 6 \text { - quant. } \\
\text { de resp. }\end{array}$ & $\begin{array}{l}\text { Subcategorias - } \\
\text { quant. de resp. }\end{array}$ & Comentários/Exemplos \\
\hline Sim - 2 & $\begin{array}{l}\text { Sem } \\
\text { subcategorias }\end{array}$ & $\begin{array}{l}\text { Apenas uma das respostas neste grupo expôs justificativa: } \\
\text { "Porque se até hoje conseguimos chegar até aqui, nos } \\
\text { sustentar" (A25). }\end{array}$ \\
\hline Não Sei - 4 & $\begin{array}{l}\text { Sem } \\
\text { subcategorias }\end{array}$ & $\begin{array}{l}\text { Estes estudantes escreveram "Não sei” em seus questionários, } \\
\text { apontando falta de reflexão ou interesse em responder a } \\
\text { questão. }\end{array}$ \\
\hline \multirow[t]{4}{*}{ Não - 20} & $\begin{array}{l}\text { Não, sem } \\
\text { explicação - } 2\end{array}$ & As respostas possuem apenas a marcação na opção "não". \\
\hline & $\begin{array}{l}\text { Não, com } \\
\text { justificativa sem } \\
\text { argumentos - } \\
10\end{array}$ & $\begin{array}{l}\text { Chamam atenção duas respostas: "Não sei porque não tem" } \\
\text { (A17), que admite claramente não saber o motivo de o planeta } \\
\text { não ter condições de se sustentar; e a "Pois com o consumo } \\
\text { abusivo, não só de coisas do meio ambiente, como as coisas } \\
\text { que não possuem a este meio, o planeta não aguentará } \\
\text { sozinho, temos que fazer a nossa parte", que abre brecha para } \\
\text { dúvidas quanto à conceituação adequada de meio ambiente, já } \\
\text { que exclui algumas "coisas" que, segundo esta resposta, não } \\
\text { pertencem a este meio. }\end{array}$ \\
\hline & $\begin{array}{l}\text { Não, com } \\
\text { justificativa } \\
\text { simplista }-4\end{array}$ & $\begin{array}{l}\text { A resposta "A sociedade para se sustentar na questão do lixo, } \\
\text { teria que se conscientizar e fazer por onde" (A2) trata somente } \\
\text { da questão do lixo; a "Por que a sociedade vem acabando cada } \\
\text { vez mas com a natureza. Buscando desenvolvimento" (A5) } \\
\text { atribui a busca pelo desenvolvimento como a razão pela } \\
\text { degradação ambiental; a A14 comenta somente da poluição } \\
\text { causada pelo grande consumo; e a A15 relaciona o atual nível } \\
\text { de consumo com o aumento constante na produção de } \\
\text { materiais. }\end{array}$ \\
\hline & $\begin{array}{l}\text { Não, com } \\
\text { justificativa } \\
\text { mais } \\
\text { argumentada- } \\
4\end{array}$ & $\begin{array}{l}\text { "Os humanos jogam grande quantidade de lixo e gases tóxicos } \\
\text { no meio ambiente, além de poluírem os rios e desmatarem as } \\
\text { florestas, e tudo isso acontece num ritmo muito acelerado, se } \\
\text { tudo continuar do jeito que está vai chegar o momento em que } \\
\text { o planeta não terá condições de se sustentar" (A1) }\end{array}$ \\
\hline
\end{tabular}

Fonte: Autoria própria.

Com o objetivo de captar o interesse dos estudantes em esclarecer dúvidas específicas, a questão 7 "Escreva algumas dúvidas que você gostaria de esclarecer sobre os temas a seguir: questões ambientais, Unidades de Conservação, biomas, recursos naturais e consumo" foi oferecida, com cinco opções bases de temas para os estudantes.

A ideia de oferecer as opções era estimular aqueles alunos que prontamente respondem não ter dúvidas, a pensar sobre alguns eixos de assuntos antes de definirem tal posição. Além disso, os blocos de assuntos favorecem a sistematização de interesses dos estudantes, auxiliando no planejamento das próximas atividades a serem desenvolvidas.

No momento da aplicação foi ressaltado aos jovens que poderiam escrever dúvidas sobre temas diversos que eles não achassem contemplados pelos temas propostos. Na tabela 4 pode-se observar a tabulação das respostas dos estudantes. 
Ensino, Saúde e Ambiente - V10 (2), pp. 1-15, Ago. 2017

Tabela 4: Categorias, subcategorias e comentários/exemplos da questão 7.

\begin{tabular}{|l|l|}
\hline $\begin{array}{l}\text { Categorias da questão 7 - quant. } \\
\text { de resp. }\end{array}$ & Comentários/Exemplos \\
\hline Não sei - 5 & $\begin{array}{l}\text { Os estudantes escreveram explicitamente que não sabiam } \\
\text { responder. }\end{array}$ \\
\hline Nenhuma dúvida -5 & $\begin{array}{l}\text { Os estudantes escreveram explicitamente que não possuíam } \\
\text { dúvidas. }\end{array}$ \\
\hline Dúvidas indeterminadas - 3 & $\begin{array}{l}\text { Esta categoria agrupa respostas generalizadas, que não permitiram } \\
\text { clareza sobre quais eram os questionamentos dos estudantes. } \\
\text { Exemplos: "O que são?" (A9), "Não sei a diferença entre elas" } \\
\text { (A5) e "O que é, para que serve e como é usado" (A19). }\end{array}$ \\
\hline Questões ambientais gerais - 2 & $\begin{array}{l}\text { Exemplos: "Eu queria saber mais sobre as questões ambientais } \\
\text { todos os elementos da natureza" (A27) e "Qual é a causa de tantos } \\
\text { problemas ambientais ocorridos ao mesmo tempo" (A6). }\end{array}$ \\
\hline Consumo - 1 & $\begin{array}{l}\text { Ressalta-se que a resposta "As coisas consumidas por nós que } \\
\text { prejudicam o meio ambiente em seu processo de extração e } \\
\text { fabricação" (A7) demonstra o entendimento de alguma relação } \\
\text { adequada entre a extração e a produção de materiais consumidos } \\
\text { com a degradação ambiental. Da mesma forma, evidencia vontade } \\
\text { em aprofundar esse entendimento. }\end{array}$ \\
\hline $\begin{array}{l}\text { Biomas e/ou Unidades de } \\
\text { Conservação - 9 }\end{array}$ & $\begin{array}{l}\text { Devido à complementaridade de os assuntos apresentam, os } \\
\text { questionamentos sobre Biomas e/ou Unidades de Conservação } \\
\text { foram agrupados. Destaca-se que na resposta "Há animais ou } \\
\text { plantas instintas nessas unidades de conservação, ou ainda não?" } \\
\text { (A4) a palavra "instintas" provavelmente tenha sido grafada } \\
\text { errado e a palavra correta seja "extintas". Outros exemplos são: } \\
\text { "A diferença entre os biomas e como funcionam as unidades de } \\
\text { conservação" (A1) e "O que é unidades de conservação?" (A17). }\end{array}$ \\
\hline
\end{tabular}

Fonte: Autoria própria.

Devido a características peculiares, que destoavam completamente das demais, a resposta "Consumo de "ervas medicinais' ou cogumelos, quando será legalizado?" (A2) foi excluída na categorização. Informa-se que, pelo histórico do(a) estudante, conhecido através de relatos da professora titular, o(a) mesmo(a) é usuário(a) de drogas, como outros alunos da escola, o que pode estar relacionado ao questionamento por ele(a) feito. $\mathrm{O}$ (a) estudante fez comentários similares ao longo dos encontros diretamente à pesquisadora. Sempre que possível foram oferecidas respostas de forma séria e embasadas em informações médicas/científicas. Quando necessário, para evitar certas extrapolações cometidas pelo(a) estudante, foi solicitada a retomada para o assunto do encontro.

A lista de Hábitos e Atitudes foi aplicada no encontro 1 da SD e seus resultados estão na tabela 5. O objetivo desta atividade era recolher uma listagem de práticas dos estudantes e extrair os temas mencionados pelos estudantes (considerados como categorias das respostas), pois é provável que os assuntos expostos pelos alunos sejam mais relevantes para estes. As categorias podem ser divididas ainda em 


\section{Ensino, Saúde e Ambiente - V10 (2), pp. 1-15, Ago. 2017}

subcategorias de acordo com o tipo de atitude (positiva ou negativa) associada a ela pelas respostas dos estudantes. Entendem-se como atitudes vinculadas a um perfil mais sustentável, aquelas que evitem ou mitiguem a degradação ambiental, estejam vinculadas a um relacionamento mais harmônico e de preocupação com o ambiente ou ainda que apresentem indícios de preocupação e engajamento social.

Tabela 5: Categorização das respostas da lista de hábitos e atitudes.

\begin{tabular}{|c|c|c|c|}
\hline Tema - Categoria & $\begin{array}{c}\text { Total de } \\
\text { respostas }\end{array}$ & $\begin{array}{c}\text { Atitudes } \\
\text { positivas }\end{array}$ & $\begin{array}{c}\text { Atitudes } \\
\text { negativas }\end{array}$ \\
\hline Lixo & 37 & 27 & 10 \\
\hline Água & 34 & 27 & 7 \\
\hline Energia elétrica & 15 & 10 & 5 \\
\hline Transporte & 8 & 4 & 4 \\
\hline Flora & 8 & 7 & 1 \\
\hline Desperdício & 8 & 6 & 2 \\
\hline Ar & 3 & 3 & 0 \\
\hline Meio Ambiente & 2 & 2 & 0 \\
\hline Outros & 13 & 10 & 3 \\
\hline
\end{tabular}

Fonte: Autoria própria.

Percebe-se, assim, que o tema mais citado pelos estudantes foi referente ao Lixo, no qual foram associadas atitudes positivas, como: não jogar lixo em local inadequado (20), não queimar lixo e objetos (6) e colocar o lixo para fora (1). Como exemplos de atitudes negativas, temos: jogar lixo no chão (6), queimar o lixo e "coisas" (2), e não separar o lixo para coleta seletiva (2). Esse resultado, juntamente com as respostas e os questionamentos (interesses) informados pelos estudantes no questionário inicial balizaram o delineamento das atividades seguintes na $\mathrm{SD}$, de forma que o assunto fosse aprofundado.

A produção final, realizada no terceiro encontro, foi definida em conjunto com os estudantes, que organizaram uma peça teatral abordando os temas trabalhados nos encontros. $\mathrm{O}$ foco da apresentação foi o despejo inadequado e a reutilização do lixo, como pode ser percebido em uma das falas da personagem que trabalhava com reutilização do lixo: “(...) faço minhas artes com algo que possa ser reutilizado para não agredirmos tanto ao mundo e faço minhas artes para vendê-las a quem goste".

A peça "Mudar o hoje para melhorar o amanhã" foi realizada pelos estudantes e apresentada para as demais turmas da escola durante o projeto anual sobre Meio Ambiente na instituição. Os estudantes definiram todos os elementos da peça teatral: enredo, cenário, falas dos personagens, etc.

De acordo com a participação, as falas e a apresentação dos estudantes, 
percebe-se o envolvimento ativo e interessado da maioria deles na atividade. Alguns alunos, aproximadamente cinco, mostraram certo desânimo e desinteresse ao longo das atividades. Mas, durante sua participação na peça teatral, em que cantaram um rap sobre o cuidado com o meio ambiente composto por eles para a plateia, o grupo de alunos pareceu à vontade e com gosto pelo resultado. Isso pode indicar que o uso de diferentes estratégias ajudou neste caso.

\section{CONSIDERAÇÕES FINAIS}

Apresentou-se neste trabalho uma SD como uma ferramenta didática para a abordagem de questões socioambientais a partir de um viés CTS, compreendendo os problemas vivenciados a partir de aspectos sociais, políticos, econômicos e ambientais.

Os resultados apontam para o interesse dos jovens em relação ao assunto abordado na SD. Apesar disso, a maioria das respostas não apresentou justificativa ou se mostrou com poucos argumentos, indicando a necessidade de novas abordagens para a identificação de dificuldades dos estudantes e/ou desinteresse e para o desenvolvimento de novas habilidades de escrita e linguagem adequada.

O lixo foi o tema mais mencionado pelos estudantes na lista de hábitos e atitudes, o que inspirou o planejamento das atividades posteriores da SD e a produção final da SD, representada pela peça teatral. Buscou-se estimular o entendimento dos alunos em relação a toda cadeia de exploração, transformação, distribuição, comercialização e descarte de produtos.

Acredita-se ser importante tratar do assunto desta maneira, pois amplia os conhecimentos e a visão dos estudantes e pode auxiliar na mudança de hábitos e atitudes em relação a vários aspectos da cadeia de produção e o ciclo de vida dos bens de consumo, por mais que tais aspectos não sejam foco de análise e avaliação neste trabalho.

\section{REFERENCIAS}

ACEVEDO-DÍAZ, J. A.; MANASSERO-MAS, M. A.; VÁZQUEZ-ALONSO, Á. Nuevos retos educativos: Hacia una orientación CTS de la alfabetización científica y tecnológica. Revista Pensamiento Educativo, Santiago, Chile, v. 30, p. 15-34, 2002. AULER, D. Alfabetização Científico-Tecnológica: Um novo "paradigma"? Ensaio, Pesquisa em Educação em Ciências, Belo Horizonte, v. 5, n. 1, p. 68-83, 2003. AULER, D.; DELIZOICOV, D. Alfabetização científico-tecnológica para quê? Ensaio, Pesquisa em Educação em Ciências, Belo Horizonte, Minas Gerais, Brasil, v. 3, n. 1, 13 p, 2001.

BARDIN, L. Análise de conteúdo. Lisboa: Edições 70, 1979.

BRASIL. Constituição (1988). Constituição da República Federativa do Brasil. 
Brasília, DF: Senado, 1988. Disponível em:

http://www.planalto.gov.br/ccivil_03/constituicao/constituicao.htm. Acesso em jan.

2017.

BRASIL. Diretrizes Curriculares Nacionais Gerais da Educação Básica. Ministério da Educação. Secretaria de Educação Básica. Diretoria de Currículos e Educação Integral. Brasília: MEC, SEB, DICEI, 2013. 562 p. Disponível em:

http://portal.mec.gov.br/index.php?option=com_docman\&view=download\&alias $=1344$ 8-diretrizes-curiculares-nacionais-2013-pdf\&Itemid=30192. Acesso em jan. 2017. BRASIL. Lei 13.005, de 25 de junho de 2014. Aprova o Plano Nacional de Educação, e dá outras providências. Disponível em:

https://www.planalto.gov.br/ccivil_03/_ato2011-2014/2014/lei/113005.htm. Acesso em jan. 2017.

BRASIL. Lei 9.394, de 20 de dezembro de 1996. Estabelece as Diretrizes e Bases da Educação Nacional. Disponível em:

http://www.planalto.gov.br/ccivil_03/Leis/L9394.htm. Acesso em 24 dez. 2016. BRASIL. Orientações Curriculares para o Ensino Médio. Volume 2: Ciências da natureza, matemática e suas tecnologias. Ministério da Educação. Secretaria de Educação Básica. Brasília. 2006. 135 p. Disponível em:

http://portal.mec.gov.br/seb/arquivos/pdf/book_volume_02_internet.pdf. Acesso em jan. 2017.

DOLZ, J.; NOVERRAZ, M.; SCHNEUWLY, B. Sequências didáticas para o oral e a escrita: apresentação de um procedimento. In: DOLZ, J.; SCHNEUWLY, B. e colaboradores. Gêneros orais e escritos na escola. Trad. E Org. de Roxane Rojo e Glaís Sales Cordeiro. Campinas, SP: Mercado das Letras, 2004. p. 95-128. Disponível em: https://profletrasuefs.files.wordpress.com/2015/03/sequc3aancias-dide3alticaspara-o-oral-e-a-escrita-1.pdf. Acesso em jan. 2017.

GIL, A. C. Como elaborar projetos de pesquisa. $5^{\text {a }}$ ed. São Paulo: Atlas, 2010. 184p. JACOBI, Pedro. Educação Ambiental, Cidadania e Sustentabilidade. In: Cadernos de Pesquisa, Fundação Carlos Chagas, v. 118, 2003. p. 189-205.

KRASILCHIK, M. Reformas e realidade: o caso do ensino das ciências. São Paulo em Perspectiva, v. 14, n. 1. jan./mar. 2000.

NOVA ESCOLA. O dia a dia do professor: como se preparar para os desafios da sala de aula. $1^{\text {a }}$ ed. Rio de Janeiro: Nova Fronteira; São Paulo: Nova Escola, 2014, 192 p.

PRAIA, J.; GIL-PÉREZ, D.; VILCHES, A. O papel da Natureza da Ciência na educação para a cidadania. Ciência \& Educação, Bauru, São Paulo, Brasil, v. 13, n. 2, p. 141-156, 2007.

QUINTAS, J. S. Educação no processo de gestão ambiental: Uma proposta de educação ambiental transformadora e emancipatória. In: LAYRARGUES, P. P. (coord).

Identidades da educação ambiental brasileira / Ministério do Meio Ambiente. Diretoria de Educação Ambiental; Ministério do Meio Ambiente, 2004. p. 113-140.

REIS, P.; GALVÃO, C. Os professores de Ciências naturais e a discussão de controvérsias sociocientifícas: dois casos distintos. Revista electrónica de Enseñanza de las Ciencias. v. 7, n. 3, p. 746-772, 2008.

VILAS BOAS, A., SILVA, M. R. DA, PASSOS, M. M., \& ARRUDA, S. DE M. História da ciência e natureza da ciência: debates e consensos. Caderno Brasileiro de Ensino de Física, Florianópolis, v. 30, n. 2, p. 287-322, 2013.

ZABALA, A. Prática Educativa: como ensinar. Porto Alegre: ARTMED, 1998. ZABALA, A.; ARNAU, L. La enseñanza de las competencias. Revista Aula de innovación educativa. España. n. 161. p. 40-46, 2007. 